\title{
Flora do Rio de Janeiro: Typhaceae
}

\author{
Flora of Rio de Janeiro: Typhaceae
}

\author{
Yasmin de Mello Canalli ${ }^{1}$ \& Claudia Petean Bove ${ }^{2}$
}

\begin{abstract}
Resumo
O presente estudo tem como objetivo contribuir para o conhecimento das espécies da família Typhaceae Juss. ocorrentes no estado do Rio de Janeiro. O trabalho tem por base a análise morfológica de materiais depositados em herbários e coletas de campo, além da compilação de dados de literatura. Foi registrada uma espécie: Typha domingensis. Descrições, ilustrações, dados sobre hábitat e distribuição geográfica da espécie são apresentados.

Palavras-chave: Sudeste do Brasil, taxonomia, planta aquática, taboa.
\end{abstract}

\begin{abstract}
This study aims to contribute to the knowledge of Typhaceae Juss. family species occurring in the state of Rio de Janeiro. The work is based on the morphological analysis of materials deposited in herbarium collections and field, besides the literature data collection. One was recorded species: Typha domingensis. Descriptions, illustrations, data on habitat and geographical distribution of the species are presented.
\end{abstract}

Key words: Brazil's Southeast, taxonomy, aquatic plant, cattail.

\section{Typhaceae Juss.}

Ervas aquáticas, emergentes, raro submersas ou flutuantes (Sparganium), paludosas ou lacustres, perenes, monoicas. Rizoma rico em amido. Caule aéreo ereto ou ausente, cilíndrico ou triangular. Folhas alternas dísticas, simples, sésseis, com bainha, lineares, alongadas, cartáceas ou coriáceas. Inflorescência composta em espiga ou capítulos globosos (Sparganium), 1 a várias, femininas na base e masculinas no ápice. Flores unissexuais numerosas, bracteoladas ou não, (1-)3-4(6) tépalas verdes ou tricomas numerosos ou ambos ausentes; estames $1-6$, anteras basifixas; ovário 1(2,3)-locular, uniovulado, estilete curto simples ou bifurcado, estigma papiloso ou não. Fruto pequeno, seco, subdrupáceo ou tipo aquênio.

Typhaceae, de distribuição cosmopolita, possui dois gêneros (APGIV 2016): Sparganium L., com ca. de 19 espécies (Kun \& Simpson 2010), não ocorre nos neotrópicos e Typha L., com ca. de 15 espécies (Smith 1967), das quais três ocorrem no Brasil (Bove 2014). Estes gêneros eram considerados famílias (monotípicas) independentes, sendo Sparganium incluído em Typhaceae recentemente (APGIV 2016).

\section{Typha L.}

Erva 1-4 m, falso caule ereto, simples, cilíndrico. Folhas glabras, margem inteira, catáfilos dísticos, caducos. Inflorescência de porção superior cônica e inferior cilíndrica, separadas por ráquis secundária e brácteas foliáceas caducas. Flores muito pequenas; estaminadas na porção superior, com bractéolas filiformes a espatulado-lanceoladas, estames 1-2(5), anteras oblongas, conectivo apiculado, pólen em mônades ou tétrades; pistiladas férteis e estéreis na porção inferior, com ou sem bractéolas, ginopódio filiforme com perianto reduzido a tricomas, ovário obovoide, unicarpelar, estigma lanceolado ou filiforme, não papiloso. Fruto aquênio-folicular.

Ocorre em áreas brejosas, borda de rios e lagoas onde pode formar grandes aglomerados. Conhecida popularmente como taboa (Reitz 1984). No Rio de Janeiro ocorre apenas uma espécie.

\footnotetext{
${ }^{1}$ Universidade Federal do Rio de Janeiro, Depto. Botânica, Museu Nacional, Quinta da Boa Vista s/n, São Cristóvão, 20940-040, Rio de Janeiro, RJ, Brasil. yasmincanalli@hotmail.com

${ }^{2}$ Universidade Federal do Rio de Janeiro, Depto. Botânica, Museu Nacional, Quinta da Boa Vista s/n, São Cristóvão, 20940-040, Rio de Janeiro, RJ, Brasil. cpbove@hotmail.com
} 
1.1. Typha domingensis Pers., Syn. P1. 2: 532. 1807.

Erva de 1-2,5 m. Folhas 4,6-13,5 × 0,5-2,5 $\mathrm{cm}$, cartáceas. Inflorescência estaminada 95-280 $\times$ 4-20 mm; inflorescência pistilada 40-360 × 8-25 mm; ráquis entre as porções estaminada e pistilada 0,3-19 $\mathrm{cm}$ comp., brácteas 14-23 $\mathrm{cm}$ comp. Flores masculinas, bractéolas 3-4, filiformes, $2,4 \mathrm{~cm}$ comp., filetes 1-2 $\mathrm{mm}$ comp., anteras 2-3 mm comp., pólen em mônade; flores femininas férteis com perianto reduzido a tricomas de 4-8 $\mathrm{mm}$ comp., bractéolas espatuladas a lanceoladas, $3-10 \mathrm{~mm}$, ginopódio 1-4 mm, ovário obovoide 1-2 mm, estilete 1-4 $\mathrm{mm}$, filiforme; femininas estéreis com tricomas de 3-6 mm, bractéolas semelhantes às férteis, 5-6 mm. Frutos fusiformes.

No Rio de Janeiro ocorre em T24, Q21, J36, N30, O29, R17, T20, M32, P28, U12, T22, B29, R12. Seu registro em herbário não reflete sua ampla distribuição no estado. Provavelmente a falta de coletas seja pelo tamanho dos indivíduos e ambiente de fundo lodoso, que dificultam a coleta e herborização. Também pode ser um agravante as grandes populações muito comuns em diversos lugares, não despertando o interesse dos taxonomistas. É encontrada em águas doces ou salobras de forma abundante, porém é muito resistente a hipersalinidade (Bove \& Paz 2009). Floresce $\mathrm{o}$ ano inteiro.

Muito utilizada para artesanato. O rizoma é usado para fabricação de bolos, a espiga pode ser cozida e assada como milho verde. O pólen é anticoagulante. A paina é usada na fabricação de travesseiro. A semente contém óleo, a fibra é boa para vedação contra água e isolante térmico. Serve para biofertilizante ou biogás (Pott \& Pott 2000). Ilustrações encontradas em Kronfeld (1894), Crespo \& Perez-Horeau (1967), Reitz (1984) e Bove \& Paz (2009).

Material selecionado: Araruama, Estrada PontinhaGigi, alagado temporário, 11.II.2000, fr., C.B. Moreira et al. 85 (R). Cachoeira de Macacu, Guapiaçu (REGUA), 27.VIII.2011, fl., A.A.M. de Barros, 4368 (RFFP). Carapebus, Lagoa Paulista, 22.X.2003, fl, C.P. Bove et al. 1310 (R). Macaé, Frade, próx. ao rio São João, após o campo de futebol. 10.X.2012, f1., Y.M. Canalli et al. 17 (R). Magé, 1.XI.1987, fl. L.C.G. Giordano 366 (RB). Maricá, Itaipuaçu, rua 31 com rua 55, em solo úmido, 12.II.2000, fr. R. Anjo \& L. Borré 24 (R). Paracambi, estrada Japeri-Paracambi, próx. ao túnel, 1.X.2012, fl., Y.M. Canalli et al. 15 (R). Quissamã, Lagoa
Preta, margem, 25.X.2006, fl., C.P. Bove et al. 1772 $(R)$. Rio das Ostras, lagoa do Iriri, 23.IX.2012, fl, Y.M. Canalli et al. 4 (R). Rio de Janeiro, Recreio, alagado, 5.IV.2012, fr., A. Donza et al. 162 (R). São João da Barra, Atafona, III. 1939, fr., A. Sampaio 8099 (R). Saquarema, Reserva Ecológica Estadual de Jacarepiá, loteamento Villatur, 28.IX.2008, fl., A.A.M. de Barros 3362 (RFFP). Varre-Sai, Fazenda Bela Vista, brejo, 27.VII.1966, fl., C. Martins (HB 39668).

\section{Agradecimentos}

A Andréia D.R. Moreira, o auxílio em diversas etapas deste trabalho. Aos curadores e equipe dos herbários RFFP, HB, R, RB. Ao Conselho Nacional de Desenvolvimento Científico e Tecnológico (Edital PROTAX, Processo 562251/2010-3), a bolsa de Produtividade de C.P.B., e a bolsa de Iniciação Científica CNPq/PIBIC de Y.M.C.

\section{Referências}

BFG 2015. Growing knowledge: an overview of seed plant diversity in Brazil. Rodriguésia 66: 1085-1113.

Bove, C.P. \& Paz, J. 2009. Guia de campo das plantas aquáticas do Parque Nacional da Restinga de Jurubatiba, Rio de Janeiro, Brasil. Série livros 35. Museu Nacional, Rio de Janeiro. 176p.

Crespo, S. \& Perez-Horeau, R.L. 1967. Revisión del género Typha en la Argentina. Darwiniana 14: 413-429.

Kronfeld, P.M. 1894. Typhaceae. In: Martius, C.P.F., Eichler, A.W. \& Urban, I. (eds.). Flora brasiliensis. Lipsiae, Frid. Fleischer. Vol. 3, pars 3, pp. 635-642, tab. 115.

Kun, S. \& Simpson, A.D. 2010. Typhaceae. In: Zhengyi, W.; Raven, P.H. \& Deyuan, H. (eds). Flora of China. Vol. 23: 158-163. Disponível em <http://flora.huh.harvard.edu/china/mss/ volume23/Flora_of_China_Vol_23_Typhaceae. pdf $>$. Acesso em 29 agosto 2012 .

Pott, V.J. \& Pott, A. 2000. Plantas aquáticas do Pantanal.Embrapa, Brasília. 404p.

Reitz, R. 1984. Tifáceas. In: Reitz, P.R. (ed.). Flora Ilustrada Catarinense, Itajaí. Part. 1, fasc. Tif. Pp. 1-14.

Smith, S.G. 1967. Experimental and natural hybrids in North American Typha (Typhaceae). The American Midland Naturalist 78: 257-287.

Smith, S.G. 2000. Typhaceae. In: Flora of North America Editorial Committee (eds.). Flora of North America. Vol. 22. Oxford University Press, New York. Pp. 158-163.

Woodson, R.E. 1943. Typhaceae. Flora of Panama. Annals of the Missouri Botanical Garden 30: 99. 


\section{Lista de exsicatas}

Anjos R. 24 (1.1). Barros A.A.M. de 4368 (1.1), 336 (1.1), 3362 (1.1). Barros R.R. 2 (1.1). Bove, C.P. 1753 (1.1), 1772 (1.1), 1310 (1.1), 344 (1.1). Canalli, Y.M. de 2 (1.1), 3 (2.1), 4 (1.1), 15 (1.1), 16 (2.1), 17 (1.1), 18 (1.1). Diogo J.C. 100 (1.1). Dionísio 1933 (1.1). Donza A. 162 (1.1). Eunice s.n.(R 103887) (1.1). Fromm E. 50 (1.1). Giordano L.C.G. 366 (1.1), 355 (1.1). Lisbôa R.M. 26 (1.1), 14 (1.1). Martins C.M. s.n.(HB 39668) (1.1). Moreira C.B. 45 (1.1), 85 (1.1), 69 (1.1). Neto L. 88 (1.1). Pabst G.F.J. 5670 (1.1). Pabst L.F. s.n.(HB 28761) (1.1). Pereira E. 8115 (1.1). Pinheiro F. 127 (1.1). Sampaio, A. 8899 (1.1). Schwacke 6994 (1.1). Senna-Valle L. 208779 (1.1). 